\title{
Derivation of Sea Surface Tidal Current From Spaceborne SAR Constellation Data
}

\author{
Yongzheng Ren, Xiao-Ming Li, Member, IEEE, GuoPing Gao, and Thomas Edmund Busche
}

\begin{abstract}
In this paper, we demonstrate an application of spaceborne synthetic aperture radar (SAR) constellation data to derive sea surface tidal current at high spatial resolution. The maximum cross correlation (MCC) method, which has been widely applied to optical remote sensing data to derive sea surface velocities, is applied to $X$-band SAR data from TerraSAR-X (TSX) and TanDEM-X (TDX), which were operating in pursuit monostatic mode. Because of the short temporal interval of TSX and TDX's pursuit acquisitions, temporal decorrelation is minimized to derive tidal current fields that exhibit significant temporal and spatial variations. In addition, we combined data from TDX and another X-band SAR, COSMOSkyMed, to obtain a virtual SAR constellation data pair, which was also analyzed using the MCC method to derive the tidal current field. Case studies of Hangzhou Bay in the East China Sea and Amrum Island in the North Sea are presented. The SAR-derived tidal current fields were compared to the results of numerical model simulations, high-frequency (HF) radar measurements and in situ measurements. MCC coefficients that are greater than 0.8 are an appropriate threshold for the further derivation of tidal currents. Comparisons to finite volume community ocean model, HF radar and general estuarine transport model results yield root-mean-square errors of 0.13 , 0.06 , and $0.05 \mathrm{~m} / \mathrm{s}$, respectively. Measurements from three field stations were also compared to the MCC SAR retrievals, yielding differences of $0.3,0.07$, and $-0.09 \mathrm{~m} / \mathrm{s}$.
\end{abstract}

Index Terms-Maximum cross correlation (MCC), tidal current field retrieval, $X$-band synthetic aperture radar (SAR) constellation.

\section{INTRODUCTION}

$\mathbf{T}$ HE extraction of sea surface velocities with satellite remote sensing techniques has received increasing attention since the 1980 s because remote sensing is a cost-effective technology that provides large spatial coverage and global

Manuscript received March 10, 2016; revised June 5, 2016, August 1, 2016, November 27, 2016, and January 23, 2017; accepted January 24, 2017. Date of publication March 1, 2017; date of current version May 19, 2017. This work was supported in part by the National Key Research and Development Program of China under Grant 2016YFC1401002, in part by the National Natural Science Foundation of China under Grant 41406198 and Grant 41471309, in part by the Hainan Province Key Science and Technology Project under Grant ZDKJ2016015, and in part by the Key Projects of the Science and Technology Commission of Shanghai Municipality under Grant 13230502000.

Y. Ren and X.-M. Li are with the Key Laboratory of Digital Earth Science, Institute of Remote Sensing and Digital Earth, Chinese Academy of Sciences, Beijing 100094, China, and also with the Hainan Key Laboratory of Earth Observation, Sanya 572029, China (e-mail: renyz@radi.ac.cn; lixm@radi.ac.cn).

G. Gao is with the College of Marine Sciences, Shanghai Ocean University, Shanghai 201306, China (e-mail: gpgao@shou.edu.cn).

T. E. Busche is with the Microwaves and Radar Institute, German Aerospace Center, 82234 Wessling, Germany (e-mail: thomas.busche@dlr.de).

Color versions of one or more of the figures in this paper are available online at http://ieeexplore.ieee.org.

Digital Object Identifier 10.1109/TGRS.2017.2666086 acquisition of satellite data. While spaceborne radar altimeters are specifically designed to measure global surface geostrophic ocean currents, novel methodologies are also available to derive sea surface velocities at high spatial resolutions over regional seas and coastal zones with optical remote sensing and synthetic aperture radar (SAR) data.

The along-track interferometry (ATI) technique [1]-[4] is currently an optimal method of deriving high-spatialresolution sea surface current fields. Before the launch of TerraSAR-X (TSX) and TanDEM-X (TDX), the ATI technique had not been utilized for spaceborne SAR. The derivation of tidal current fields in coastal zones with TSX/TDX data was performed using the TSX data that were collected in dual receive antenna mode (i.e., splitting the single TSX antenna into two parts) [3] and the TDX bistatic ATI data [4]. In addition to the ATI technique, the SAR Doppler centroid method [5]-[7] has demonstrated its ability to derive sea surface velocities, particularly in areas with strong western boundary currents, such as those described in [8]. However, the ATI and Doppler centroid methods yield the line-of-sight components of the sea surface vectors instead of the full vectors.

The maximum cross correlation (MCC) method of deriving sea surface velocities from sequential satellite images was first demonstrated by Emery et al. [9], who used data from the Advanced Very High Resolution Radiometer (AVHRR) presenting the sea surface temperature gradient that was induced by the advection of sea water. Following this demonstration, a number of studies [10]-[20] further illustrated the advantages of the MCC method in deriving sea surface velocities of different regional seas with sequential optical remote sensing images, particularly the AVHRR data. In addition to the sea surface temperature gradients that are evident in satellite thermal images, the ocean color front as imaged by optical remote sensors has been used to derive sea surface velocities with the MCC method [11], [18], [21]-[23].

However, the sea surface velocities that are calculated from thermal satellite data with the MCC method cannot be used in regions where thermal gradients are weak and thus are often affected to some extent by air-sea interactions [11]. Furthermore, this method is inhibited by weather because thermal and optical remote sensing data cannot be acquired under cloudy conditions. Meanwhile, the sequential optical remote sensing images that are used to derive sea surface velocities via the MCC method usually have temporal intervals that vary from hours to days depending on the satellites' revisiting time. Therefore, a common application is to map the sea 
surface velocities in areas of strong western boundary currents; however, this method cannot address the large tempo-spatial variations in typical diurnal or semi-diurnal tidal currents in coastal zones and river estuaries.

In addition, feature tracking has been applied to SAR imagery in several studies to estimate sea surface velocities based on the principle of the MCC method. Slicks that float on the sea surface can reduce the measured radar backscatter by damping surface capillary waves, which can be primarily explained by the Marangoni's damping theory but is also related with other factors, e.g., energy input by the wind [24]. Macro-algal blooms, in contrast with sea surface slicks, can enhance the measured radar backscatter as found in X-band SAR images [25]. Therefore, sea surface velocities could be derived through tracking the spatial variations of radar backscatter (often presenting as dark or bright patches in SAR images) caused by surface slicks or macro-algal blooms. Lyzenga and Marmorino [26] used oceanic surface slick tracking to obtain surface currents and current gradients based on a pair of airborne SAR images with time intervals of $20 \mathrm{~min}$, and the results compared well to acoustic Doppler current profiler (ADCP) currents. Surface currents have been estimated in a few cases through surface slicks in spiral-eddy convergence zones by airborne SAR images at time separations of around $1.5 \mathrm{~h}$ [27]. ENVISAT and ERS-2 have the same orbit, so Liu and Hsu [28] demonstrated the application of deriving sea surface velocities through the wavelet feature tracking of surface slicks in a pair of EVNISAT advanced SAR (ASAR) and ERS-2 SAR images, which had a time interval of 28 min. Recently, Qazi et al. [29] estimated surface currents over coastal California by using an ERS-2 SAR and ENVISAT ASAR data pair based on the MCC method. And the SAR derived surface current has a higher magnitude than the high-frequency (HF) radar measurements by approximately $11 \mathrm{~cm}$. The tracking of sea surface slicks to derive sea surface velocities is not limited to a single type of spaceborne sensor. Gade et al. [22] demonstrated such an application in the Baltic Sea with multiple satellite data from the thematic mapper, ERS-2 SAR, ENVISAT ASAR, wide-field scanner, and the Sea-Viewing Wide Field-of-View Sensor (SeaWIFS). The derived surface currents from the multiple satellite acquisitions are generally larger than those provided by the numerical models, whereas they present small-scale turbulent structures which are resolved by the operational models.

The X-band spaceborne SARs of TSX and TDX can be operated in a bistatic ATI configuration and in pursuit monostatic mode; the latter refers to the independent operation of TSX and TDX to acquire images over the same area with temporal intervals of several seconds [30]. Therefore, we can minimize temporal de-correlation by using TSX and TDX pursuit monostatic mode data to extract sea surface velocities that exhibit significant temporal variations based on the MCC method. In addition, small surface variations in tidal currents will be mapped because of the high spatial resolution of the SAR data. In this paper, we demonstrate the possibility to retrieve tidal currents in coastal oceans by applying the MCC method to X-band SAR data with high spatial resolution.
Descriptions of the data are provided in Section II. The MCC method is briefly introduced in Section III. Case studies of Hangzhou Bay in the East China Sea and Amrum Island in the North Sea are presented in Section IV. The results are discussed following the case studies. In the last section, the study is summarized and conclusions are drawn.

\section{DESCRIPTIONS OF THE SAR DATA AND DATA FOR COMPARISON}

Spaceborne SAR data that were acquired by TSX and TDX when operating in pursuit monostatic mode and data from COSMO-SkyMed (CSK) were used in this paper. The derived sea surface current fields were compared to finite volume community ocean model (FVCOM) simulations, HF radar data, and in situ measurements that were acquired during a field campaign.

\section{A. TSX/TDX Pursuit Monostatic Mode Data}

When in pursuit monostatic mode, TSX and TDX operate independently. The time interval of the TSX/TDX pursuit monostatic mode data that were used in this paper was $10 \mathrm{~s}$. The SAR images were acquired in stripmap mode with a pixel size of approximately $3 \mathrm{~m}$. The data pairs for Hangzhou Bay in the East China Sea and Amrum Island (Germany) in the North Sea were acquired on December 3, 2014 and on February 26, 2015 , respectively.

\section{B. CSK Data}

The CSK constellation consists of four satellites that are equipped with SAR sensors, which together yield a high revisit frequency. However, we used data from TDX that were collected in stripmap mode in combination with data from one CSK SAR sensor to form a virtual SAR constellation data pair with a temporal interval of several seconds between the two acquisitions for the case study of Hangzhou Bay.

\section{HF Radar Measurements and GETM Reanalysis Data}

$\mathrm{HF}$ radar relies on the first- and second-order scattering of HF electromagnetic waves from the ocean surface and can be used to achieve high-accuracy real-time monitoring of the marine environment over a large area through the extraction of the marine and meteorological parameters of sea surface winds, waves, and currents from radar echoes [31], [32]. In this paper, the HF data for the sea surface current field around Amrum Island were obtained from the Coastal Observing System for Northern and Artic Seas (COSYNA) data portal; these data are available for every $20 \mathrm{~min}$ with a spatial resolution of $1.5 \mathrm{~km}$ in range and $3^{\circ}$ in azimuth. Every hour, these HF data are assimilated into a 3-D hydrodynamic model [the general estuarine transport model (GETM)] [33]. The GETM reanalysis data were also obtained from the COSYNA data portal and are available at a regular grid size of $1.0 \mathrm{~km}$.

\section{In Situ Measurements}

In this paper, field measurements of sea surface currents were obtained during an expedition that was conducted on July 


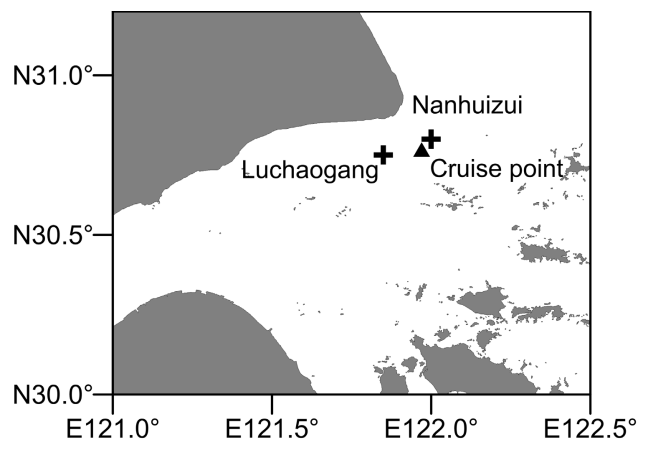

Fig. 1. Map that shows the moored ADCP stations (cross) and a match-up location of the expedition in Hangzhou Bay with the SAR acquisitions on July 22, 2015.

22, 2015 in Hangzhou Bay. The locations of the field stations are shown in Fig. 1. An ADCP (Workhorse Sentinel, Teledyne RD Instruments) that was towed alongside the boat was used to measure the in situ near-surface currents at a depth of 0.5 $\mathrm{m}$ at various sites in the bay. The triangular marker in Fig. 1 indicates a location at which the cruise measurement matches up with the SAR acquisitions. In addition, the ADCP measurements were collected at two fixed sites, namely, the Nanhuizui and Luchaogang stations (indicated by the cross-shaped markers in Fig. 1), which also lie within the spatial coverage of the SAR images.

\section{E. Tidal Current Predictions From the FVCOM}

A regional barotropic tidal forecast model of Hangzhou Bay was developed based on the FVCOM (named HB-FVCOM hereafter). The FVCOM was jointly developed by the Institute of Marine Science and Technology of the University of Massachusetts and the Woods Hole Oceanographic Institute [34]. The development of the HB-FVCOM was motivated by the predicted open boundary conditions that surround the Zhoushan Archipelago, with eight major tidal constituents (M2, N2, S2, K2, K1, O1, P1, and Q1), which were obtained through interpolation from the results of the Oregon State University Tidal Inversion Software China Seas $1 / 30^{\circ}$ inverse tidal model [35]. This model was validated by using historical in situ tidal current data and surface elevation observations (not shown in this paper).

We compared the simulated surface tidal currents from the HB-FVCOM at 09:50 UTC on December 3, 2014 to the SAR-derived tidal currents based on the MCC method. The spatial resolution of the model ranges from approximately $1 \mathrm{~km}$ near the coast to $5 \mathrm{~km}$ in the open ocean region. The simulated tidal currents in irregular grids were spatially re-sampled to those in a grid size of $3 \mathrm{~km}$ for the comparison.

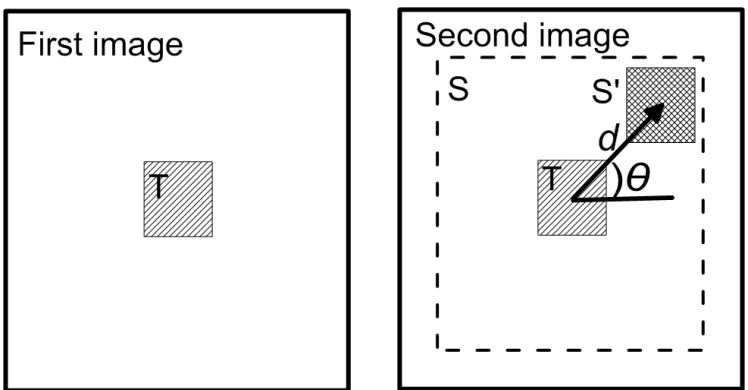

Fig. 2. Description of the MCC method that was used to derive sea surface velocities by analyzing sequential satellite images. The solid box in the first image is the template window $\mathrm{T}$, and the large dashed box in the second image is the search window $\mathrm{S}$.

\section{Methodology}

\section{A. Description of the MCC Method}

The MCC method (refer to Fig. 2) uses a sequential satellite images and performs automatic feature tracking to extract sea surface velocities.

In this paper, a region in the first SAR image was selected as the template window $T$, and then a larger region in the second SAR image was used as the search window $S$, which was centered on the same central position as $T$. The template window was allowed to move vertically and horizontally by overlapping within the search window. For pixel coordinates of $T(x, y)$ in the template window, the corresponding pixels in the search window were $S(x, y)$ at no lag and $S(x+p, y$ $+q)$ for a lag of $(p, q)$. The searched region within $S$ by the movement of the template window was called subregion $S^{\prime}$. The cross correlation coefficient $r(p, q)$ between $T$ and $S^{\prime}$ at lag $(p, q)$ used to measure the similarity between them is given in (1), shown at the bottom of the page. where $\operatorname{Cov}(p, q)$ is the covariance of $T$ and $S^{\prime} . \sigma_{S}$ and $\sigma_{T}$ are the standard deviations of $S^{\prime}$ and $T$, respectively. The location with the coordinates $\left(p_{\max }, q_{\max }\right)$ location that produces the MCC corresponds to the most likely displacement of the sea surface advection. We calculated the corresponding spatial displacement $\mathrm{d}$ by using the MCC coefficient and then derived the sea surface current speed $c$ from this spatial displacement and the time interval $\Delta t$ between the two SAR images

$$
c=d / \Delta t=\sqrt{\left(p_{\max } \Delta x\right)^{2}+\left(q_{\max } \Delta y\right)^{2}} / \Delta t .
$$

The direction of the displacement is given by $\theta$, as shown in

$$
\theta=\tan ^{-1}\left(\left(q_{\max } \Delta y\right) /\left(p_{\max } \Delta x\right)\right)
$$

where $\Delta x$ and $\Delta y$ represent the pixel sizes in range and azimuth directions, respectively. The size of the template window and the search length used in the MCC method significantly affect the results of the calculation. If the template size and search length are too small, the method cannot effectively extract the features, whereas an excessively large

$$
r(p, q)=\frac{\sum \sum\left[S^{\prime}(x+p, y+q)-\overline{S^{\prime}(x+p, y+q)}\right][T(x, y)-\overline{T(x, y)}]}{\left(\sum \sum\left[S^{\prime}(x+p, y+q)-\overline{S^{\prime}(x+p, y+q)}\right]^{2} \sum \sum[T(x, y)-\overline{T(x, y)}]^{2}\right)^{\frac{1}{2}}}=\frac{\operatorname{Cov}(p, q)}{\sigma_{S} \sigma_{T}}
$$




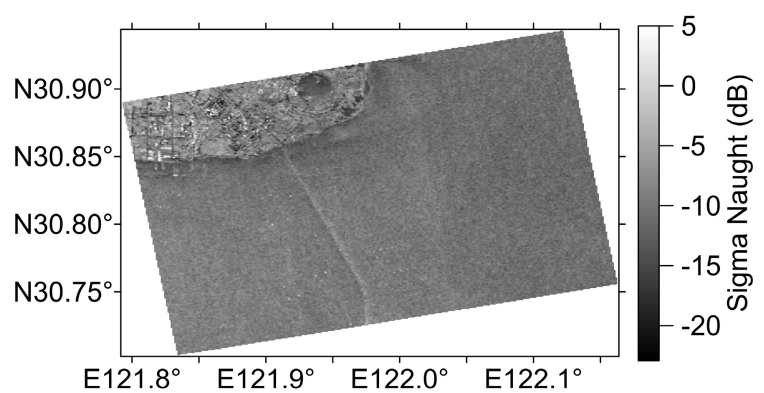

(a)

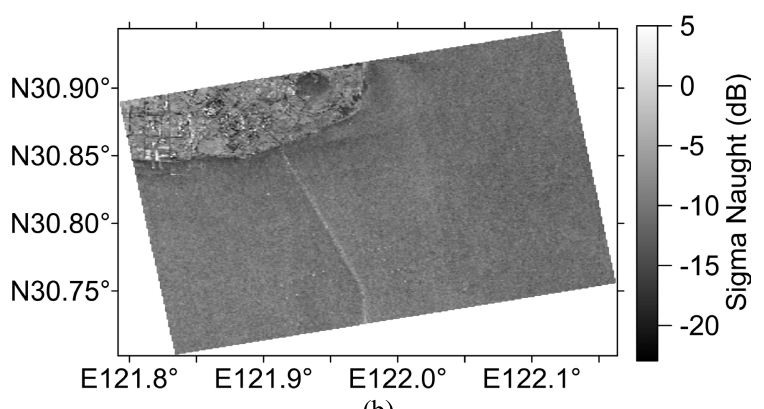

(b)

Fig. 3. Radiometrically calibrated (a) TSX and (b) TDX data acquired over the Donghai Bridge in Hangzhou Bay in the East China Sea at 09:44:44 UTC and 09:44:54 UTC, respectively, on December 3, 2014.

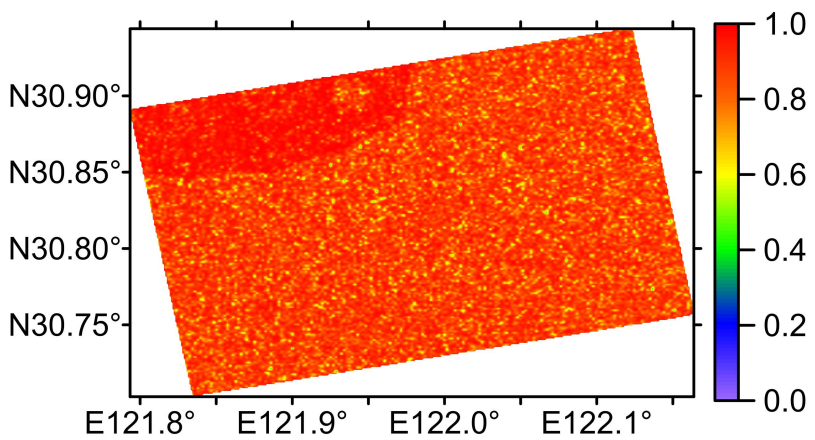

(a)

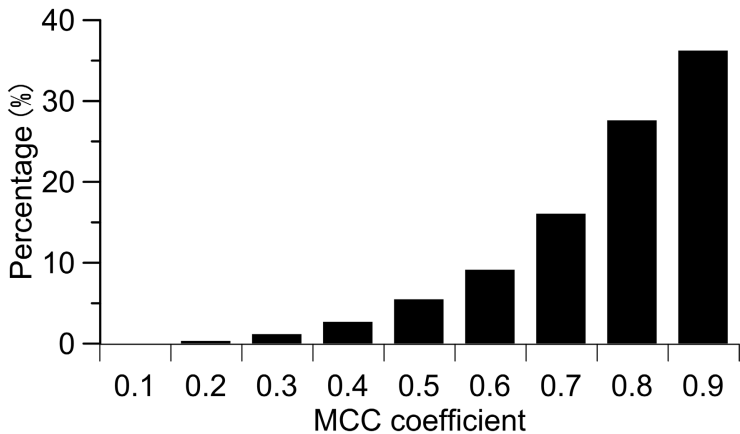

(b)

Fig. 4. (a) MCC coefficients that were calculated from the TSX/TDX data pairs in Fig. 3 and (b) corresponding histogram.

template size and search length will result in a loss of the fine structure of the sea surface current fields and a very high computational cost. Therefore, an appropriate template size and search length must be determined, and a priori knowledge of the sea surface current fields in the area of interest (AOI) is helpful for this purpose.

\section{B. Data Processing to Calculate the Sea Surface Currents}

The processing steps to calculate sea surface currents from TSX, TDX, and SCK data based on the MCC method are described in detail as follows.

The TSX, TDX, and CSK data in complex format (i.e., single-look-complex data) were converted to intensity and then radiometrically calibrated. Speckle is a common feature in SAR images because of the coherent integration of randomly distributed backscatter phases from multiple scatterers within one ground resolution cell. Therefore, the SAR intensity data were smoothed to reduce speckle noise. A box-car filter with a window size of $3 \times 3$ pixels was applied to reduce speckle noise in this paper.

The speckle-filtered TSX/TDX and TDX/CSK SAR data pairs were then co-registered. The annotation files of the TSX, TDX, and CSK data provided the geographic coordinates and incidence angles of the reference grids. The TSX/TDX and TDX/CSK image pairs were coregistered by using triangulation interpolation based on this reference information.

After preprocessing, the MCC coefficient could be calculated between two consequential SAR data according to (1). The size of the template window and the search length that is used in the MCC method are two important parameters that can significantly affect the results of the calculation. If the template size and search length are too small, the method cannot effectively extract the features, whereas an excessively large template size and search length will result in a loss of the fine structure of the sea surface current fields and induce a very high computational cost. Therefore, an appropriate template size and search length must be determined, and a priori knowledge of the sea surface current fields in the AOI is helpful for this purpose. The threshold of the MCC coefficient that was considered significant was 0.7 , as in some previous studies. Values greater than $0.7,0.8$, and 0.9 were used to estimate the current fields in the following case studies to analyze the influence of the MCC coefficient threshold on the sea surface current fields.

\section{CAse Studies}

This section presents three case studies in which the tidal current fields were derived with the MCC method for Hangzhou Bay in the East China Sea and the area to the south of Amrum Island in the North Sea. The derived current fields were compared to model simulations, HF radar measurements and in situ ADCP measurements.

\section{A. Case Study of Hangzhou Bay With TSX/TDX Pursuit Monostatic Mode Data}

Fig. 3(a) and (b) shows the TSX and TDX stripmap images that were acquired in pursuit monostatic mode over Hangzhou Bay on December 3, 2014 at 09:44:44 UTC and 09:44:54 UTC, respectively. The time interval between the two images is $10 \mathrm{~s}$. The bright line in the middle of each image is the Donghai Bridge, which connects Shanghai with Yangshan Harbor. 


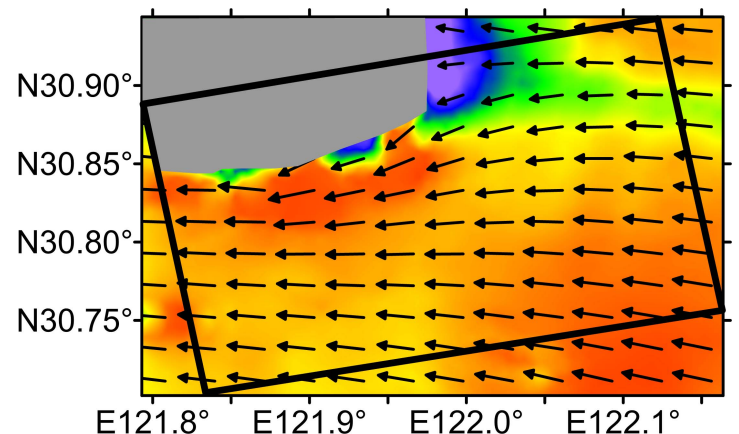

(a)

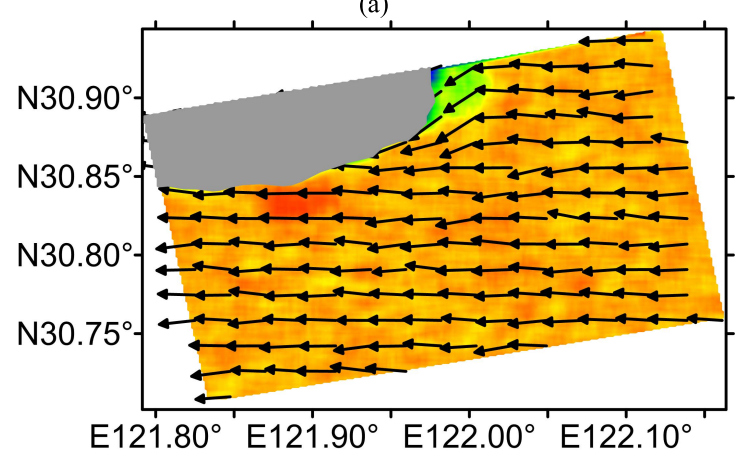

(c)

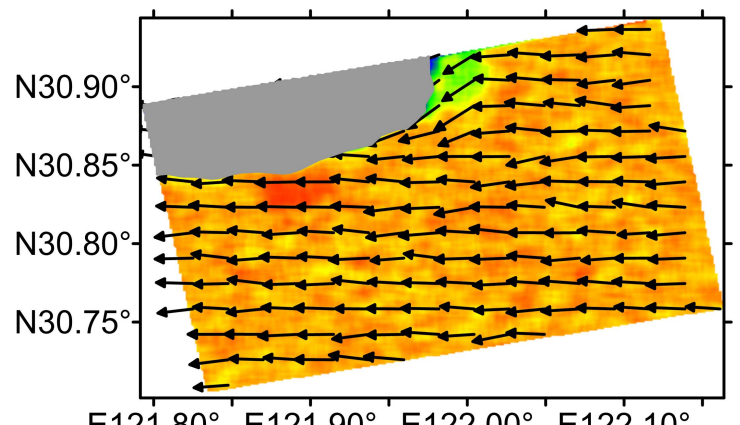

$\mathrm{E} 121.80^{\circ} \mathrm{E} 121.90^{\circ} \mathrm{E} 122.00^{\circ} \mathrm{E} 122.10^{\circ}$

(b)

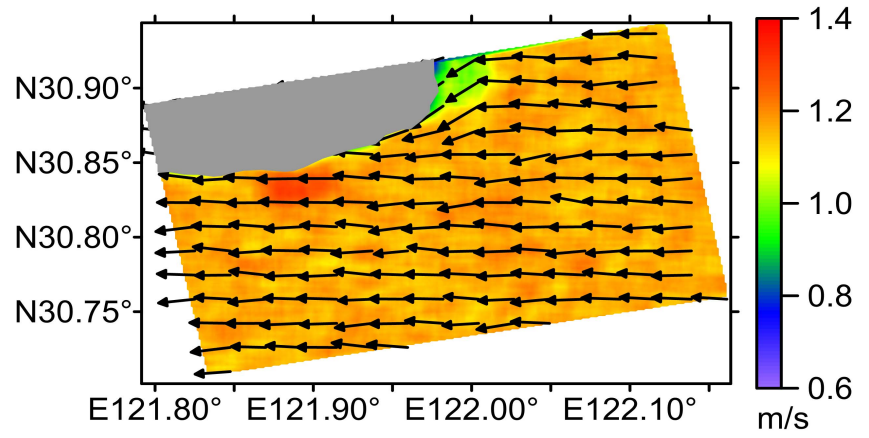

(d)

Fig. 5. (a) Simulated tidal current field by the FVCOM in Hangzhou Bay at 09:50 UTC on December 3, 2014. (b)-(d) Derived tidal currents from the TSX/TDX data pair in Fig. 3 with MCC coefficient thresholds of 0.7, 0.8, and 0.9, respectively. The black frame in (a) shows the coverage of the TSX/TDX data.

As mentioned above, some empirical knowledge of the sea surface current fields in the AOI is helpful to determine the appropriate template size and search length. Our previous study in Hangzhou Bay [36] suggested that the tidal current in the mouth of the bay can reach $1.3 \mathrm{~m} / \mathrm{s}$. Moreover, the HB-FVCOM simulation of the tidal current fields in the bay on December 3, 2014 [Fig. 5(a)] indicated a maximum tidal current speed near the Donghai Bridge of approximately $1.4 \mathrm{~m} / \mathrm{s}$, which corresponds to a sea surface displacement of approximately $14 \mathrm{~m}$ in $10 \mathrm{~s}$ (i.e., the temporal interval between the TSX and TDX acquisitions). Therefore, the size of the template window was set to $5 \times 5$ pixels, which corresponds to a spatial resolution of $15 \times 15 \mathrm{~m}$ for the derivation. The maximum search length was set to 8 pixels (i.e., $24 \mathrm{~m}$ in space), which corresponds to a maximum current speed of $2.4 \mathrm{~m} / \mathrm{s}$ over a temporal interval of $10 \mathrm{~s}$, to allow for the bias of the model prediction and to ensure that all surface changes in the tidal current fields in the bay could be tracked.

The MCC coefficients for the TSX/TDX data pairs were calculated with the above parameter configurations, as shown in Fig. 4(a). Fig. 4(b) presents the histogram of the MCC coefficients. The percentages of the MCC coefficients that fell into the intervals $0.7-0.8,0.8-0.9$, and $0.9-1.0$ were approximately $16 \%, 28 \%$, and $36 \%$, respectively. Considering the template size and realistic currents, the current fields in the bay were derived with MCC coefficients that were greater than 0.7, 0.8, and 0.9, respectively, as shown in Fig. 5. The black arrows in the figures indicate the flows on the sea surface, which were derived with (3). The arrows represent the re-sampled results for the sea surface current vectors for clarity in the figures. Some previous studies indicated that the tidal current in Hangzhou bay is very strong and is dominant in surface flow [36]. Therefore, the westward surface flows suggest that the tide was in a flood phase at the moment of the SAR acquisitions. The figures indicate that the derived current fields with the three MCC coefficient thresholds are reasonably similar and become smoother with a higher threshold.

The retrievals were further averaged to the same grid size as the FVCOM results to perform a comparison because of the higher spatial resolution of the SAR-derived tidal current fields. Fig. 6 shows the comparisons of the retrieved sea surface current speeds $X_{i}$ that were obtained from the TSX/TDX data pair by using different MCC coefficient thresholds with the HB-FVCOM results $Y_{i}$. Twenty-seven matches existed between the SAR retrieval results and the model simulation results. The bias, the root-mean-square error (RMSE), the correlation and the scatter index [SI, shown in (4)] were used in this study to assess the accuracy of the SAR retrieval. The SI is the RMSE normalized with respect to the mean value of the data set that is used for comparison. Because the current speed was relatively small, the RMSE indicates the difference between the SAR retrieval results and the validation data set, whereas the SI quantifies the difference with respect to the mean state of the current field.

These four statistical parameters (bias, RMSE, correlation and SI) were nearly identical for the thresholds of 0.8 and 0.9 , both of which yielded slightly superior results compared to the threshold of 0.7. Considering these parameters, we chose to use MCC coefficients that were greater than 0.8 to derive the tidal current fields. With this threshold, the comparison to the FVCOM results yielded a bias, RMSE, correlation and SI 


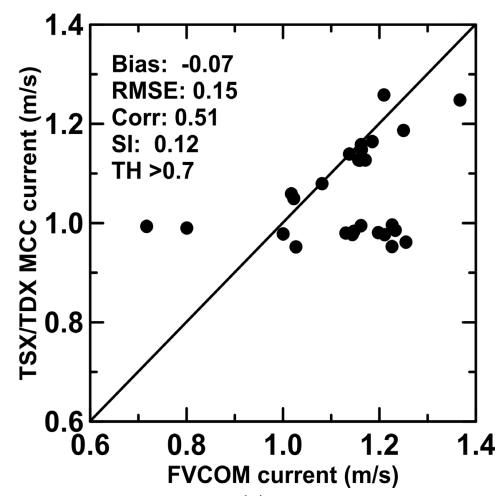

(a)

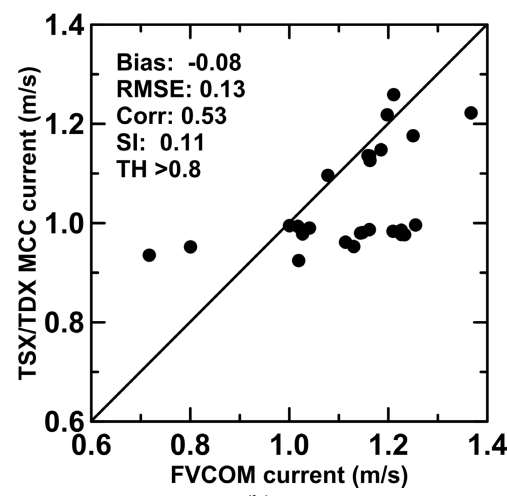

(b)

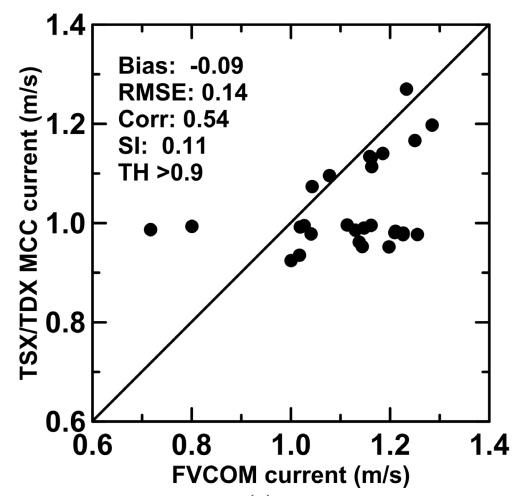

(c)

Fig. 6. Comparison of the SAR-derived tidal current speeds with the MCC coefficient thresholds of (a) 0.7, (b) 0.8, and (c) 0.9 with the results of the HB-FVCOM.

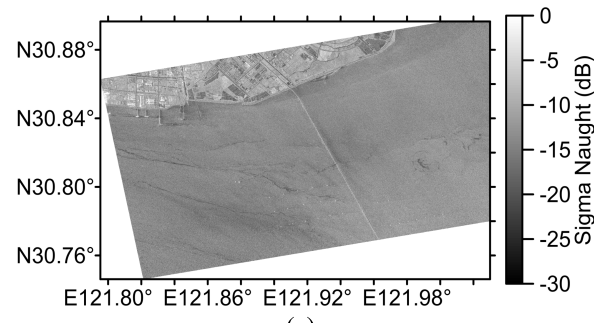

(a)

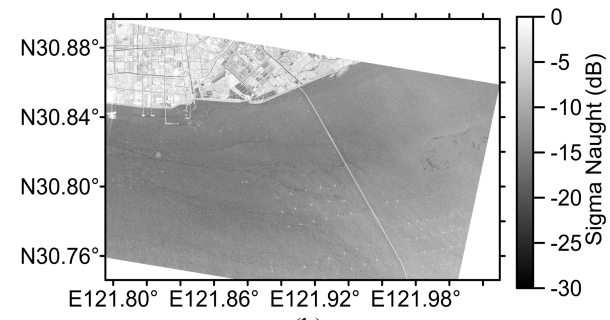

(b)

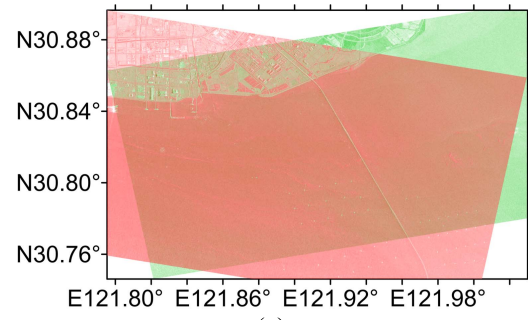

(c)

Fig. 7. Radiometrically calibrated (a) TDX and (b) CSK images that were acquired in Hangzhou Bay on July 22, 2015 at 09:44:45 UTC and 09:44:47 UTC, respectively, and (c) overlap of the two SAR scenes from the bay.

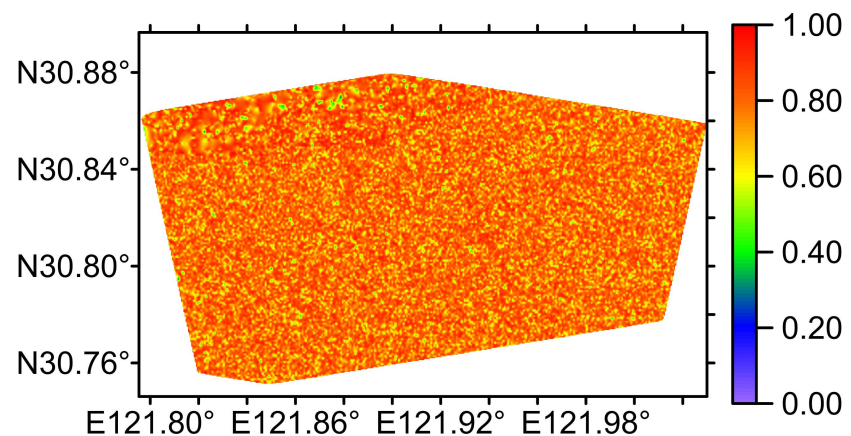

(a)

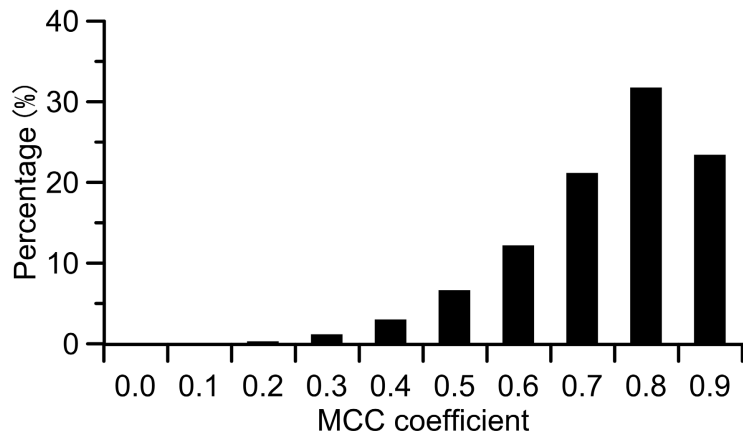

(b)

Fig. 8. (a) MCC coefficients that were calculated from the TDX/CSK data pair in Fig. 7 and (b) corresponding histogram.

of $-0.08 \mathrm{~m} / \mathrm{s}, 0.13 \mathrm{~m} / \mathrm{s}$, and 0.53 and 0.11 , respectively

$$
\mathrm{SI}=\frac{1}{\bar{X}_{i}} \sqrt{\frac{1}{n} \sum\left[\left(Y_{i}-\bar{Y}_{i}\right)-\left(X_{i}-\bar{X}_{i}\right)\right]^{2}} .
$$

\section{B. Case Study of Hangzhou Bay With a TDX and CSK Data Pair}

In contrast to the above case study, in which TSX/TDX pursuit monostatic mode data were used, the case study in this section was performed by combining X-band SAR data from TDX and CSK to generate a virtual satellite constellation data pair, which was then used to derive the tidal current fields with the MCC method. For unknown reasons, both the TDX and CSK images that were acquired over the southern area of Hangzhou Bay were severely contaminated. Therefore, only the valid sections (over the northern area of the bay) of the two images, which were acquired at 09:44:45 UTC and 09:44:47 UTC (starting times of the scenes), respectively, on July 22,
2015, are shown in Fig. 7. The temporal intervals between the data from the two SAR images in the overlapping area [Fig. 7(c)] varied from 2 to $6 \mathrm{~s}$ because of the different orbit directions of the two satellites.

Similar to the previous case study, the size of the template window was set to $5 \times 5$ pixels $(15 \times 15 \mathrm{~m}$ in space $)$, but the search length was set to 5 pixels (15 $\mathrm{m}$ in space) because of the shorter temporal interval between the two SAR images. Fig. 8(a) shows the MCC coefficients that were calculated from the TDX and CSK data pair, and the corresponding histogram is shown in Fig. 8(b). Fig. 8(b) suggests that the largest percentage of coefficients (approximately 32\%) lies in the interval of $0.8-0.9$, which is different from the previous case in the bay on December 3, 2014.

The tidal current fields that were retrieved in this case with MCC coefficients greater than $0.7,0.8$, and 0.9 are shown in Fig. 9. The derived maximum current speed was approximately $1.4 \mathrm{~m} / \mathrm{s}$ near the area of Luchaogang Dock. 


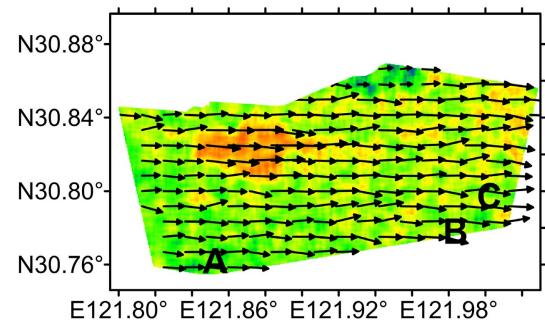

(a)

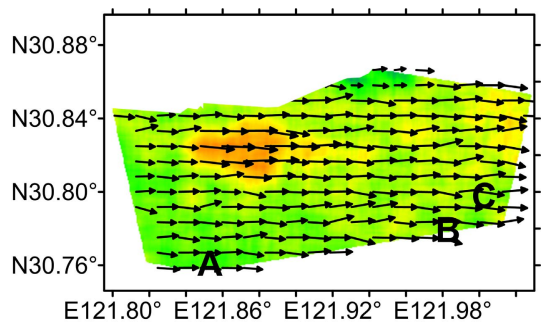

(b)

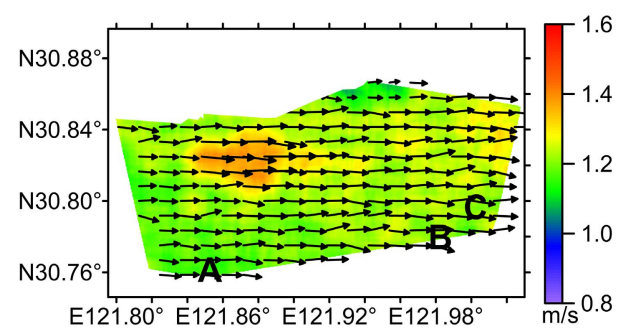

(c)

Fig. 9. Tidal current fields that were retrieved from the TDX and CSK data shown in Fig. 8 with the MCC coefficients greater than (a) 0.7, (b) 0.8, and (c) 0.9 .

TABLE I

Comparison of the Retrieved Tidal Current Velocities With the IN Situ ADCP Measurements

\begin{tabular}{|c|c|c|c|c|}
\hline Station & ADCP Measurement & MCC Coeff. & SAR Retrieval & Velocity Difference \\
\hline \multirow{3}{*}{$\begin{array}{c}\mathrm{A}\left(30.75^{\circ} \mathrm{N}, 121.85^{\circ} \mathrm{E}\right) \\
09: 45: 00 \text { UTC }\end{array}$} & \multirow{3}{*}{$0.88 \mathrm{~m} / \mathrm{s}, 89.70^{\circ}$} & $>0.7$ & $1.16 \mathrm{~m} / \mathrm{s}, 89.30^{\circ}$ & $0.28 \mathrm{~m} / \mathrm{s},-0.40^{\circ}$ \\
\hline & & $>0.8$ & $1.17 \mathrm{~m} / \mathrm{s}, 91.34^{\circ}$ & $0.29 \mathrm{~m} / \mathrm{s}, 1.64^{\circ}$ \\
\hline & & $>0.9$ & $1.16 \mathrm{~m} / \mathrm{s}, 91.46^{\circ}$ & $0.28 \mathrm{~m} / \mathrm{s}, 1.76^{\circ}$ \\
\hline \multirow{3}{*}{$\begin{array}{c}\mathrm{B}\left(30.77^{\circ} \mathrm{N}, 121.98^{\circ} \mathrm{E}\right) \\
09: 44: 44 \text { UTC }\end{array}$} & \multirow{3}{*}{$1.12 \mathrm{~m} / \mathrm{s}, 111.56^{\circ}$} & $>0.7$ & $1.11 \mathrm{~m} / \mathrm{s}, 105.06^{\circ}$ & $-0.01 \mathrm{~m} / \mathrm{s},-6.5^{\circ}$ \\
\hline & & $>0.8$ & $1.19 \mathrm{~m} / \mathrm{s}, 100.01^{\circ}$ & $0.07 \mathrm{~m} / \mathrm{s},-11.55^{\circ}$ \\
\hline & & $>0.9$ & $1.19 \mathrm{~m} / \mathrm{s}, 102.13^{\circ}$ & $0.07 \mathrm{~m} / \mathrm{s},-9.43^{\circ}$ \\
\hline \multirow{3}{*}{$\begin{array}{c}\mathrm{C}\left(30.80^{\circ} \mathrm{N}, 122.0^{\circ} \mathrm{E}\right) \\
09: 45: 00 \text { UTC }\end{array}$} & \multirow{3}{*}{$1.31 \mathrm{~m} / \mathrm{s}, 95.00^{\circ}$} & $>0.7$ & $1.18 \mathrm{~m} / \mathrm{s}, 102.96^{\circ}$ & $-0.13 \mathrm{~m} / \mathrm{s}, 7.96^{\circ}$ \\
\hline & & $>0.8$ & $1.22 \mathrm{~m} / \mathrm{s}, 94.64^{\circ}$ & $-0.09 \mathrm{~m} / \mathrm{s},-0.36^{\circ}$ \\
\hline & & $>0.9$ & $1.22 \mathrm{~m} / \mathrm{s}, 94.65^{\circ}$ & $-0.09 \mathrm{~m} / \mathrm{s},-0.35^{\circ}$ \\
\hline
\end{tabular}

Compared to the case from December 3, 2014, the retrieval for this case suggests that the tide was in an ebb phase at the moment of the SAR acquisitions, which means that the seawater was flowing eastward. Similar to the previous case, a high tidal current speed of approximately $1.4 \mathrm{~m} / \mathrm{s}$ was also observed in the area of Luchaogang Dock. This high current speed region presented in both Figs. 5 and 9 was very likely induced by the artificial alteration of coastal zones from the construction of the dock.

In these figures, the three sites where in situ measurements were performed are labeled as A, B, and C. Sites A (Luchaogang station) and $C$ (Nanhuizui station) are the two fixed stations where ADCPs were moored and correspond to the cross-shaped markers in Fig. 1, and site B is where the ADCP measurements were obtained while cruising and corresponds to the triangular marker in Fig. 1. Table I compares the derived sea surface current velocities with the in situ measurements at the three sites. For station A, the differences between the SAR retrieval results and the ADCP measurements are relatively large, reaching approximately $0.3 \mathrm{~m} / \mathrm{s}(33 \%$ of the in situ observation). However, the differences for stations $\mathrm{B}$ and $\mathrm{C}$ are generally less than $0.1 \mathrm{~m} / \mathrm{s}(<7 \%)$. The temporal interval between the two SAR images in the overlapping area [Fig. 7(c)] for station A was approximately $2.4 \mathrm{~s}$, which was shorter than those in station B by $0.6 \mathrm{~s}$ and $\mathrm{C}$ by $1.5 \mathrm{~s}$, respectively because of the different orbit directions of the two satellites. Therefore, the excessively short temporal interval between two SAR images in site A may have induced bias in the retrieval because of the actual displacement, which was smaller than one pixel. This result should partially explain why the difference between the SAR retrieval and ADCP measurements in station A was larger than those in the other two sites. If the ADCP measurements of the sea surface current fields are treated as the ground truth, the comparisons suggest that the results from the SAR constellation data with the MCC method yielded an accurate estimation of the regional tidal current fields.

\section{Case Study of Amrum Island With TSX/TDX Pursuit Monostatic Mode Data}

The last case study includes the area to the south of Amrum Island, where HF radar measurements of the sea surface current field are available. Amrum Island is located to the south of Sylt Island on the western side of the North Sea. The TSX/TDX pursuit monostatic mode data that were used in this paper were also acquired in stripmap mode on February 26, 2015 at 17:02:02 UTC and 07:02:12 UTC. Fig. 10(a) shows the spatial coverage of the TSX and TDX images, whereas Fig. 10(b) presents the TSX image.

According to the surface current field that was measured by $\mathrm{HF}$ radar [Fig. 11(a)] and obtained from the GETM reanalysis data [Fig. 11(b)] for 17:02 UTC and 17:00 UTC, respectively, on February 26, 2015, the maximum sea surface current speed near Amrum Island was approximately $0.8 \mathrm{~m} / \mathrm{s}$, so the maximum advection of the sea surface was approximately $8 \mathrm{~m}$ within the $10 \mathrm{~s}$ temporal interval between the TSX and TDX acquisitions. Therefore, the size of the template window was also set to $5 \times 5$ pixels, which corresponds to $15 \times 15 \mathrm{~m}$ in space. The maximum search length was set to 5 pixels ( $15 \mathrm{~m}$ in space) to allow surface changes to be tracked when the sea surface current speed was less than $1.5 \mathrm{~m} / \mathrm{s}$. The MCC coefficients that were derived from the TSX/TDX data pairs for this case are shown in Fig. 12(a), and the corresponding histogram is shown in Fig. 12(b). Compared to the results for Hangzhou Bay (Figs. 5 and 9), the overall 


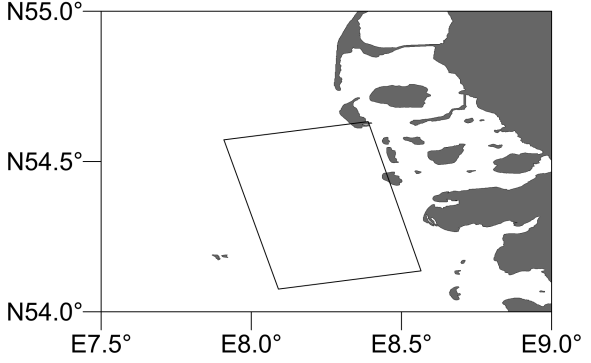

(a)

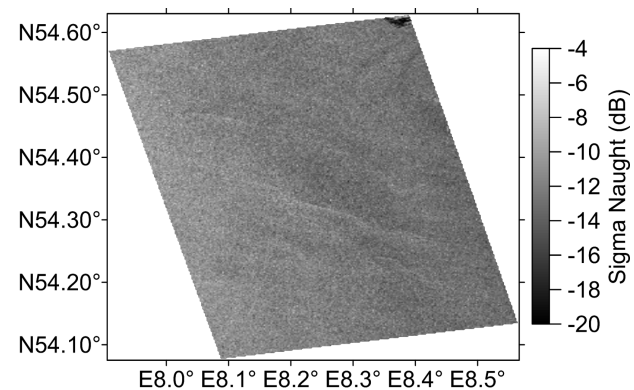

(b)

Fig. 10. (a) Illustration of the TSX/TDX spatial coverage to the south of Amrum Island and (b) radiometrically calibrated TSX data that were acquired at 17:02:02 UTC on February 26, 2015.

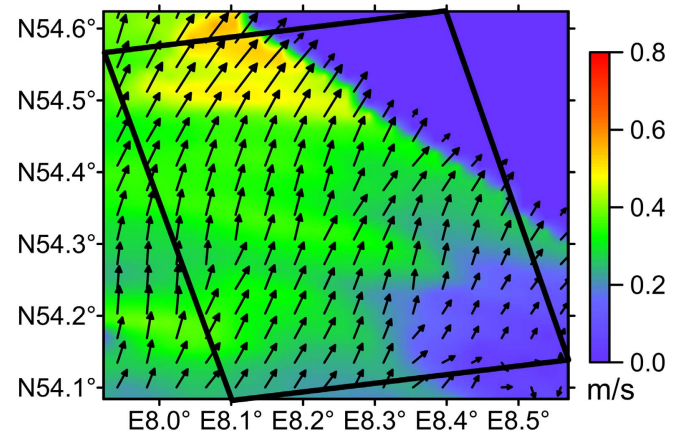

(a)

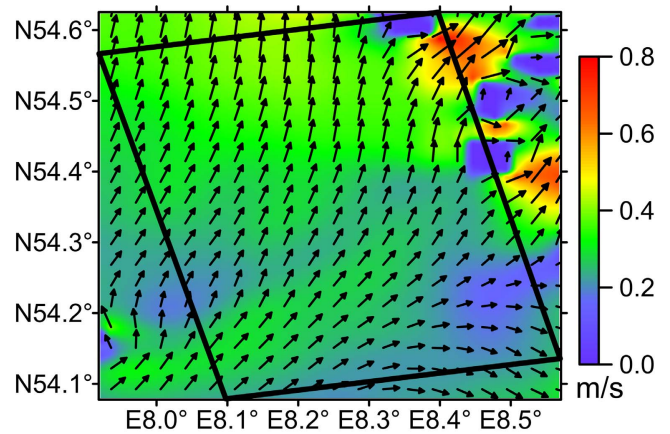

(b)

Fig. 11. Sea surface current fields that were obtained from the (a) HF radar data and (b) GETM reanalysis model at 17:02 UTC and 17:00 UTC, respectively, on February 26, 2015. The black frame shows the coverage of the TSX/TDX images.

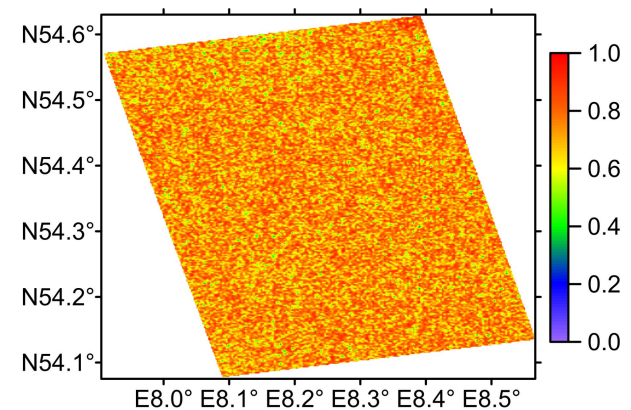

(a)

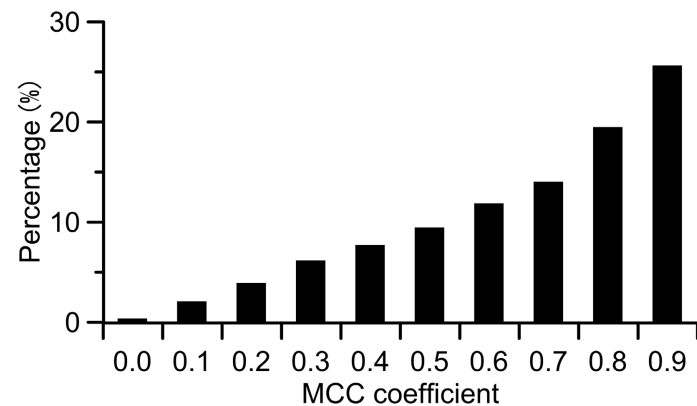

(b)

Fig. 12. (a) MCC coefficients that were derived from the TSX and TDX data pair shown in Fig. 11 and (b) corresponding histogram.

MCC coefficient values for the Amrum Island case were low, with approximately $12.5 \%$ of these values being less than 0.4 .

Similar to the previous two cases, the tidal current fields for the Amrum Island case were also calculated with MCC coefficients that were greater than $0.7,0.8$, and 0.9 , as shown in Fig. 13. The results that were derived with these three thresholds were reasonably similar, and the derived tidal current directions were consistent with the results from the HF radar measurements and the GETM reanalysis model (Fig. 11). The surface flows between Amrum Island and Hooge Island strengthened because of the funneling effect, which is consistent with the GETM reanalysis results. In addition, the derived tidal current speeds to the west of Amrum Island were consistent with the GETM reanalysis results but lower than the HF radar measurements. This relative underestimation is understood to be related to the accessed HF radar data, which are the averaged sea surface current field over $20 \mathrm{~min}$ [33]. According to a tide chart from the Federal Maritime and
Hydrographic Agency of Germany, low tide occurred at 12:06 UTC and high tide was at 17:52 UTC on February 26, 2015 at Amrum Island. From low to high tide (during the flood phase), the sea surface current speed gradually decreased, following an approximately sine-like function (semi-diurnal tide). The HF radar measurements at 17:02 actually reflect the average sea surface current speeds from 16:42 to 17:02 and are therefore greater than the current speeds at 17:02, whereas the SAR-derived tidal current speeds correspond to an instantaneous measurement at 17:02.

The SAR-derived tidal current fields had much higher spatial resolution than the HF measurements or the GETM reanalysis data and thus were further averaged to the same grid size as that of the verification data set for comparison, resulting in 943 (for the HF comparison) and 1511 (for the GETM comparison) matching data pairs in the area. Fig. 14 shows the comparison diagrams. Consistent with the similar sea surface current fields that were retrieved with the different 


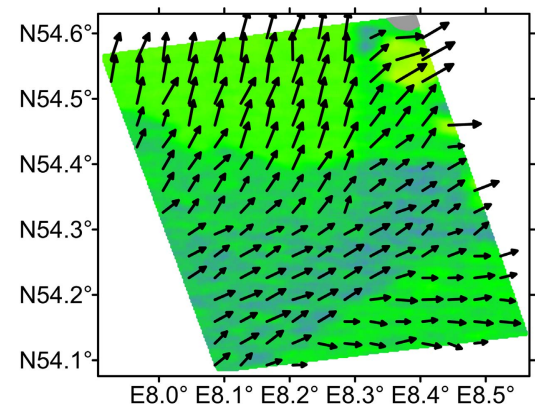

(a)

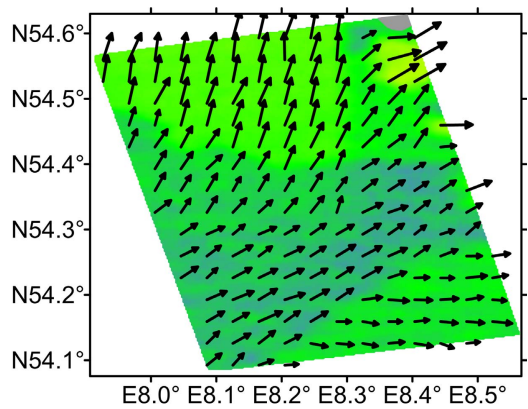

(b)

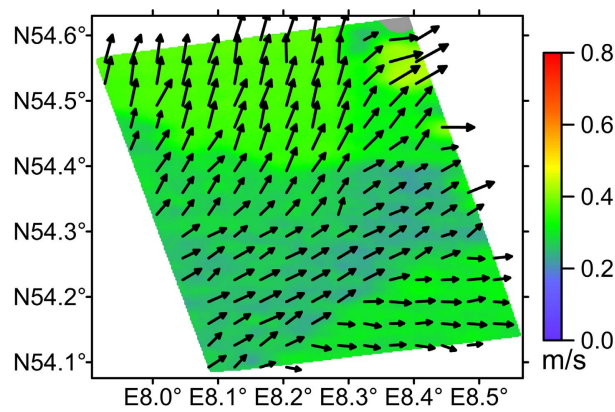

(c)

Fig. 13. Tidal currents that were retrieved via the MCC method from the TSX and TDX data pairs in Fig. 10 with the MCC coefficients greater than (a) 0.7 , (b) 0.8 , and (c) 0.9 .
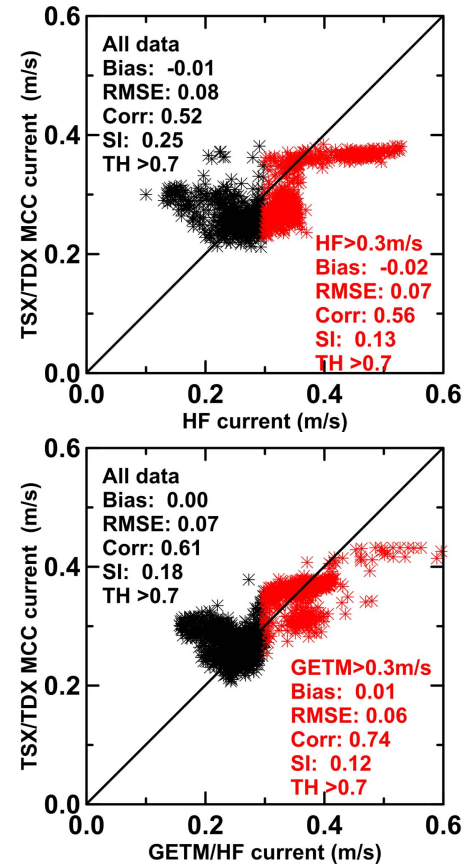

(a)
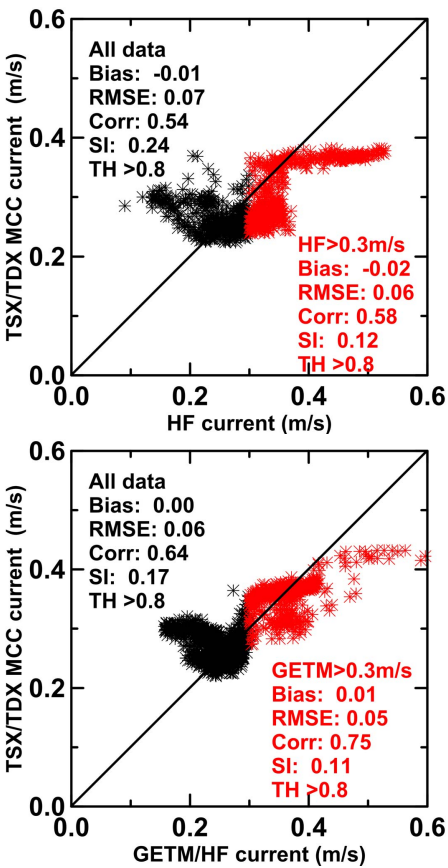

(b)
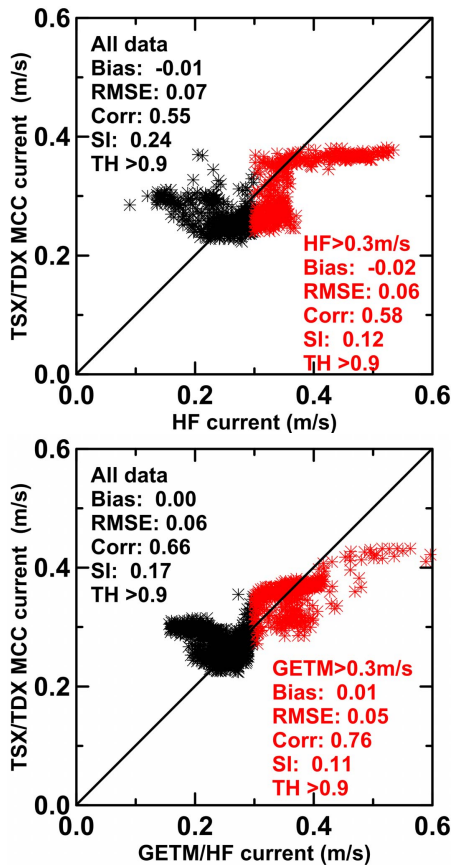

(c)

Fig. 14. Comparisons of the SAR-derived tidal current speeds with the MCC coefficients greater than (a) 0.7 , (b) 0.8 , and (c) 0.9 with the HF radar measurements (first row) and the GETM reanalysis data (second row). The red symbols represent the tidal current speeds that were obtained from the $\mathrm{HF}$ radar measurements and GETM reanalysis model results with values greater than $0.3 \mathrm{~m} / \mathrm{s}$.

MCC coefficient thresholds, the statistical comparisons with the GETM reanalysis data reveal identical bias, RMSE and correlation values, although the SI was slightly improved with a higher MCC coefficient threshold. The same trends can be observed in the comparison between the retrieved sea surface current fields and the HF radar measurements, although the bias, RMSE and SI exhibited slightly less accuracy than those for the GETM reanalysis data.

The value of the minimum tidal current speed that can be derived from SAR data with the MCC method is limited to the actual pixel size of the SAR image. In this case paper, the pixel size of the TSX and TDX images was $3 \mathrm{~m}$ and the temporal interval was $10 \mathrm{~s}$; therefore, current speeds lower than $0.3 \mathrm{~m} / \mathrm{s}$ could not be accurately derived. In total, $473 \mathrm{HF}$ radar measurements and 518 GETM reanalysis model results existed with values greater than $0.3 \mathrm{~m} / \mathrm{s}$, which are shown as red symbols in Fig. 15. In comparisons of only these higher quality data, the RMSE, correlation and SI values were all improved. In terms of the precision of the RMSE, correlation and SI, as in the two case studies of Hangzhou Bay, an MCC coefficient threshold of 0.8 was an appropriate choice to derive the sea surface current fields. With this threshold, the statistical comparison with the HF radar measurements yielded RMSE, correlation and SI values of $0.06 \mathrm{~m} / \mathrm{s}, 0.58$ and 0.12 , respectively. The SAR retrieval better matched the GETM reanalysis model results, with the corresponding statistical parameters of $0.05 \mathrm{~m} / \mathrm{s}, 0.75$, and 0.11 , respectively.

\section{Discussion}

Although the MCC method was applied to SAR constellation data with short temporal intervals on the order of a few seconds to derive tidal currents, no noticeable features, e.g., surface slicks, were present in the SAR images, which differs from previous studies. A consequential question is exactly what was tracked during the MCC calculations.

Two transects (longitude $121.85^{\circ}$ and $122.10^{\circ}$, marked $\mathrm{T} 1$ and T2) were selected in the TSX and TDX images for the case on December 3, 2014 to compare the variation in 


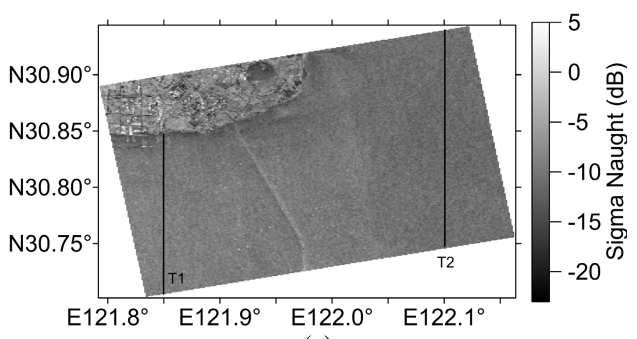

(a)

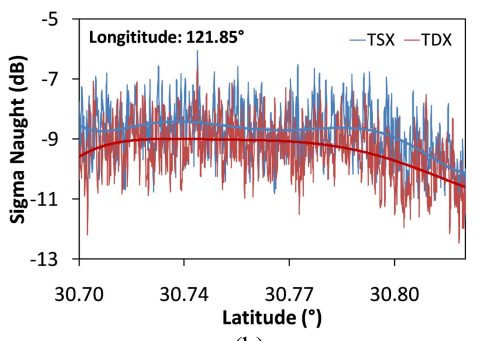

(b)

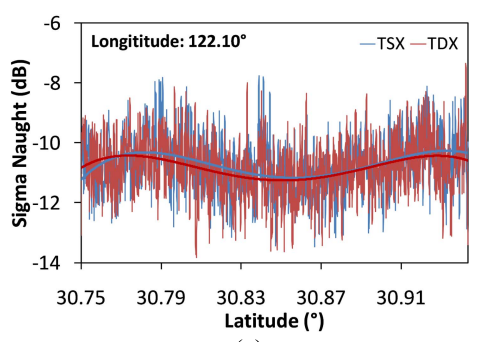

(c)

Fig. 15. Comparisons of the variation in the sea surface radar backscatter of the TSX and TDX images that were acquired with a $10 \mathrm{~s}$ temporal interval in the case on December 3, 2014. (a) Locations of two transects from the TSX and TDX images and (b) and (c) distribution of the sea surface radar backscatter of the two images for transections T1 and T2, respectively. The blue and red folded lines represent the radar backscatter distribution for transections $\mathrm{T} 1$ and $\mathrm{T} 2$ from the TSX and TDX images, and the blue and red curves are the corresponding trend lines.

the sea surface radar backscatter of the two images, which were acquired with a $10 \mathrm{~s}$ temporal interval, as illuminated in Fig. 15. Fig. 15(b) and (c) shows the variations in the normalized radar cross section (NRCS) of the two transects. The blue and red lines represent the NRCS of the TSX and TDX data, and the continuous curves are the corresponding trend lines. Similar radar backscatter intensity patterns and shifts in these patterns existed between the two SAR images; the principle of the MCC method is to find similarities between two signals. Therefore, similarities in the sea surface NRCS of two SAR images that were acquired with very short temporal intervals were derived through MCC calculations in this paper.

The sea surface is principally imaged by SAR via Bragg scattering, in which transmitted radar waves are reflected back to the antenna by short surface waves that ride on the tilted surfaces of longer waves [37]; these short surface waves, or generally called capillary waves, are generated by wind. When an ocean current is present, wave-current interactions modify the wavenumbers and amplitudes of these capillary waves, which propagate varying surface currents and further induce variations in sea surface radar backscatter. Fig. 15(b) and (c) shows variations in sea surface radar backscattering within a small temporal scale of $10 \mathrm{~s}$, which should be attributed to variations in sea surface current because the radar backscatter that is induced by sea surface wind should remain consistent with such a short temporal interval. The test sites in this paper were selected where tidal currents were dominant and strong, such as in Hangzhou Bay. Although the imaged sea surface roughness by SAR is influenced by multiple oceanic processes, the significant variations in NRCS that are tracked within a very short temporal interval can reflect the tidal current field.

The second issue that is discussed here involves comparisons of SAR-derived tidal currents with other data sets. In the case from December 3, 2014 in Hangzhou Bay, the tidal current field simulated by the HB-FVCOM model had a relatively coarse resolution and could not resolve the fine features of current fields in the bay; however, this model did provide information, e.g., the general magnitude and direction of the tidal current field for verification when no ground truth data were available. Moreover, the HB-FVCOM currents that were used were simulated and averaged over the top $1 \mathrm{~m}$ of the ocean surface. The direct comparisons that were performed in this paper may have introduced some biases, while the SAR-derived results were the sea surface tidal current field.
The same issue was also found for the Amrum Island case in the comparison with the HF radar measurements, which were the averaged sea surface current field, including wind currents, tidal currents and geostrophic currents over the top $1 \mathrm{~m}$ of the ocean [38]. Furthermore, the HF radar measurements were the averaged current fields over $20 \mathrm{~min}$, whereas the SAR-derived results corresponded to an instantaneous measurement. Both the above factors created some differences between them.

The ADCP measurements should be treated as ground truth. However, the three ADCPs for the case on July 22, 2015, were located at a depth of $0.5 \mathrm{~m}$ below the sea surface to perform measurements in Hangzhou Bay. Moreover, the ADCPs measured the current vectors with a vertical resolution of $0.25 \mathrm{~m}$. Thus, the obtained current fields in this case were indeed the averaged results over a depth of $0.5-0.75 \mathrm{~m}$, which should have created slight differences with the SAR-derived results along the sea surface.

Nevertheless, numerical modeling, HF radar and ADCP measurements are often used to verify satellite observations, and the results in the previous section suggest that the MCC method can be applied to SAR constellation data to derive tidal currents in coastal zones. However, this application also has its drawbacks. On the one hand, the minimum current speed that can be derived is limited by the pixel size and the temporal interval of the two consecutive SAR images. On the other hand, the accuracy of the derived current speed depends on the geolocation accuracy of the SAR data. The TSX and TDX images in this paper, which were recorded in stripmap mode with a geolocation accuracy of $1 \mathrm{~m}$, could have induced a bias of $0.1 \mathrm{~m} / \mathrm{s}(1 \mathrm{~m} / 10 \mathrm{~s})$, which is acceptable for high tidal current speed, e.g., in Hangzhou Bay, but is relatively high for low current speeds, e.g., the North Sea case.

\section{Summary AND CONCLUSION}

The MCC method is traditionally applied to optical remote sensing data to derive sea surface velocities and presumes that the features of ocean surfaces are essentially in constant motion. The diurnal or semi-diurnal tide current fields in coastal zones and river estuaries exhibit large spatial and temporal variations and therefore are hardly derived from sequential satellite images with temporal intervals of hours to days. Shortening the temporal interval between sequential satellite images is an effective method to minimize temporal 
de-correlation to improve accuracy of the extracted sea surface velocities with the MCC method. Previous studies that derived surface currents with the MCC method have relied on sequential SAR images that contain visible surface slicks or biological characteristics; however, this scenario was not the case for the images in this paper, which show rather homogenous sea surface features. Although further theory analysis, e.g., based on the M4S model [39], [40], is demanded to verify which are exactly tracked when the MCC method is applied to two SAR images separated by very short temporal intervals while sea surface slicks are absent, the case studies presented here suggest it is possible for the retrieval of sea surface current fields in coastal oceans with the MCC method applied to SAR images acquired in pursuit monostatic mode.

The tidal current field in Hangzhou Bay is strong and that its tidal features can be captured in high-spatial-resolution SAR images; therefore, we selected this area as an "ideal" test site for the proposed method. In this study's Hangzhou Bay cases, the tidal current fields were extracted via the MCC method by using two different sets of images: one consisted of TSX and TDX satellite constellation data that were collected in pursuit monostatic mode for the same sea area with a $10 \mathrm{~s}$ imaging time interval, and the other consisted of data that were collected by TDX and CSK in a "virtual" pursuit mode with an even shorter temporal interval of 2-6 s. In the first Hangzhou Bay case on December 3, 2014, the tidal current in the bay was strong and the sea surface wind speed at the moment of the TSX and TDX acquisitions was approximately $5 \mathrm{~m} / \mathrm{s}$, as derived from the SAR data, so we compared the derived tidal current fields with simulated tidal currents from the HB-FVCOM. An in situ campaign was conducted in the second Hangzhou Bay case, so the measured (sub) sea surface current from the ADCP was compared to the SAR-derived results. Comparisons of the Hangzhou Bay case studies suggested that the proposed method could yield realistic estimates of the tidal current fields in the bay.

For the case near Amrum Island, the comparisons of the derived sea surface current fields with HF measurements and GETM reanalysis results indicated that the SAR retrievals were more consistent with the GETM reanalysis results than with the HF radar measurements because the accessed HF measurements actually represent surface velocities that were averaged over $20 \mathrm{~min}$ in temporal space and $1 \mathrm{~m}$ in water depth. The minimum tidal current speed that could be accurately derived in this case was approximately $0.3 \mathrm{~m} / \mathrm{s}$ because of the limitations from the pixel size of the SAR images. When the speeds that were less than $0.3 \mathrm{~m} / \mathrm{s}$ were excluded, the comparisons yielded improved values for the statistical parameters.

All three cases in this study suggest that MCC coefficients that are greater than 0.8 are appropriate to derive tidal current fields from SAR data pairs with the previously described configurations. A priori knowledge of the tidal current fields can assist in determining the most effective template window size and search length for a particular case. If no such knowledge is available, the search length can be increased to ensure that surface changes are tracked, but doing so can incur a greater computational cost.
Although the pursuit monostatic mode of TSX and TDX is a unique configuration that has not been implemented for other SAR sensors, our case study with TDX/CSK data pairs indicates that the proposed method may have broad applicability, particularly with the increasing availability of spaceborne SAR constellation data, including data from Sentinel-1A, Sentinel1B, and the planned RADARSAT Constellation Mission.

\section{ACKNOWLEDGMENT}

The authors would like to thank the reviewers for many valuable comments and suggestions, which were a great help in the improvement of the manuscript. The TSX/TDX data were kindly provided by DLR via the AO proposal OCEA0524. The CSK data are copyrighted by the Italian Space Agency. The HF radar data and GETM reanalysis data were downloaded from the COSYNA data portal CODM (http://codm.hzg.de/codm/).

\section{REFERENCES}

[1] R. M. Goldstein and H. A. Zebker, "Interferometric radar measurement of ocean surface currents," Nature, vol. 328, pp. 707-709, Aug. 1987.

[2] R. M. Goldstein, T. P. Barnett, and H. A. Zebker, "Remote sensing of ocean currents," Science, vol. 246, pp. 1282-1285, Dec. 1989.

[3] R. Romeiser, S. Suchandt, H. Runge, U. Steinbrecher, and S. Grunler, "First analysis of TerraSAR-X along-track InSAR-derived current fields," IEEE Trans. Geosci. Remote Sens., vol. 48, no. 2, pp. 820-829, Feb. 2010.

[4] R. Romeiser, H. Runge, S. Suchandt, R. Kahle, C. Rossi, and P. S. Bell, "Quality assessment of surface current fields from TerraSAR-X and TanDEM-X along-track interferometry and Doppler centroid analysis," IEEE Trans. Geosci. Remote Sens., vol. 52, no. 5, pp. 2759-2772, May 2014.

[5] B. Chapron, F. Collard, and F. Ardhuin, "Direct measurements of ocean surface velocity from space: Interpretation and validation," J. Geophys. Res.-Oceans, vol. 110, no. C7, pp. 691-706, Jul. 2005.

[6] J. A. Johannessen et al., "Direct ocean surface velocity measurements from space: Improved quantitative interpretation of Envisat ASAR observations," Geophys. Res. Lett., vol. 35, no. 22, pp. 113-130, Nov. 2008.

[7] M. W. Hansen, F. Collard, K. Dagestad, J. A. Johannessen, P. Fabry, and B. Chapron, "Retrieval of sea surface range velocities from Envisat ASAR Doppler centroid measurements," IEEE Trans. Geosci. Remote Sens., vol. 49, no. 10, pp. 3582-3592, Oct. 2011.

[8] M. J. Rouault, A. Mouche, F. Collard, J. A. Johannessen, and B. Chapron, "Mapping the Agulhas Current from space: An assessment of ASAR surface current velocities," J. Geophys. Res.-Oceans, vol. 115, pp. 105-109, Oct. 2010.

[9] W. J. Emery, A. C. Thomas, M. J. Collins, W. R. Crawford, and D. L. Mackas, "An objective method for computing advective surface velocities from sequential infrared satellite images," J. Geophys. Res.Oceans, vol. 91, pp. 12865-12878, Nov. 1986.

[10] M. Kamachi, "Advective surface velocities derived from sequential images for rotational flow field: Limitations and applications of maximum cross-correlation method with rotational registration," J. Geophys. Res., vol. 94, pp. 18227-18233, Dec. 1989.

[11] R. Tokmakian, P. T. Strub, and J. Mcclean-Padman, "Evaluation of the maximum cross-correlation method of estimating sea surface velocities from sequential satellite images," J. Atmos. Ocean. Technol., vol. 7, pp. 852-865, Dec. 1991.

[12] W. J. Emery, C. Fowler, and C. A. Clayson, "Satellite-image-derived gulf stream currents compared with numerical model results," J. Atmos. Ocean. Technol., vol. 9, pp. 286-304, Jun. 1992.

[13] K. A. Kelly and P. T. Strub, "Comparison of velocity estimates from Advanced Very High Resolution Radiometer in the coastal transition zone," J. Geophys. Research-Oceans, vol. 97, pp. 9653-9668, Jun. 1992.

[14] Q. X. Wu, D. Pairman, S. J. Mcneill, and E. J. Barnes, "Computing advective velocities from satellite images of sea surface temperature," IEEE Trans. Geosci. Remote Sens., vol. 30, no. 1, pp. 166-176, Jan. 1992.

[15] M. M. Bowen, W. J. Emery, J. L. Wilkin, P. C. Tildesley, I. J. Barton, and R. Knewtson, "Extracting multiyear surface currents from sequential thermal imagery using the maximum cross-correlation technique," J. Atmos. Ocean. Technol., vol. 19, pp. 1665-1676, Oct. 2002. 
[16] P. O. Zavialov, J. V. Grigorieva, O. O. Möller, A. G. Kostianoy, and M. Gregoire, "Continuity preserving modified maximum cross-correlation technique," J. Geophys. Res.-Oceans, vol. 107, pp. 24-1-24-10, Oct. 2002.

[17] S. Dransfeld, G. Larnicol, and P. Y. L. Traon, "The potential of the maximum cross-correlation technique to estimate surface currents from thermal AVHRR global area coverage data," IEEE Geosci. Remote Sens. Lett., vol. 3, no. 4, pp. 508-511, Oct. 2006.

[18] R. I. Crocker, D. K. Matthews, W. J. Emery, and D. G. Baldwin, "Computing coastal ocean surface currents from infrared and ocean color satellite imagery," IEEE Trans. Geosci. Remote Sens., vol. 45, no. 2, pp. 435-447, Feb. 2007.

[19] S. R. Chubb, R. P. Mied, C. Y. Shen, W. Chen, T. E. Evans, and J. Kohut, "Ocean surface currents from AVHRR imagery: Comparison with land-based HF radar measurements," IEEE Trans. Geosci. Remote Sens., vol. 46, no. 11 , pp. 3647-3660, Nov. 2008.

[20] D. K. Matthews and W. J. Emery, "Velocity observations of the California current derived from satellite imagery," J. Geophys. Res. Oceans, vol. 114, pp. 262-263, Aug. 2009.

[21] C. A. E. Garcia and I. S. Robinson, "Sea-surface velocities in shallow seas extracted from sequential coastal zone color scanner satellite data," J. Geophys. Res.-Oceans, vol. 94, pp. 12681-12691, Sep. 1989.

[22] M. Gade, B. Seppke, and L. Dreschler-Fischer, "Mesoscale surface current fields in the Baltic Sea derived from multi-sensor satellite data," Int. J. Remote Sens., vol. 33, pp. 3122-3146, Oct. 2011.

[23] H. P. Yang, R. Arnone, and J. Jolliff, "Estimating advective near-surface currents from ocean color satellite images," Remote Sens. Environ. vol. 158, pp. 1-14, Mar. 2015.

[24] M. Gade, W. Alpers, H. Hühnerfuss, V. R. Wismann, and P. A. Lange, "On the reduction of the radar backscatter by oceanic surface films: Scatterometer measurements and their theoretical interpretation," Remote Sens. Environ., vol. 66, pp. 52-70, Oct. 1998.

[25] A. Ciappa, L. Pietranera, A. Coletta, and X. Jiang, "Surface transport detected by pairs of COSMO-SkyMed ScanSAR images in the Qingdao region (Yellow Sea) during a macro-algal bloom in July 2008," J. Marine Syst., vol. 80, pp. 135-142, Feb. 2010.

[26] D. R. Lyzenga and G. O. Marmorino, "Measurement of surface currents using sequential synthetic aperture radar images of slick patterns near the edge of the Gulf Stream," J. Geophys. Res.-Oceans, vol. 103, pp. 18769-18777, Aug. 1998.

[27] G. O. Marmorino, B. Holt, M. J. Molemaker, P. M. DiGiacomo, and M. A. Sletten, "Airborne synthetic aperture radar observations of "spiral eddy' slick patterns in the Southern California Bight," J. Geophys. Res.Oceans, vol. 115, no. C5, art. no. C05010, May 2010.

[28] A. K. Liu and M. K. Hsu, "Deriving ocean surface drift using multiple SAR sensors," Remote Sens., vol. 1, pp. 266-277, Sep. 2009.

[29] W. A. Qazi, W. J. Emery, and B. Fox-Kemper, "Computing ocean surface currents over the coastal California current system using 30-min-lag sequential SAR images," IEEE Trans. Geosci. Remote Sens., vol. 52 , no. 12 , pp. $7559-7580$, Dec. 2014.

[30] G. Krieger et al., "TanDEM-X: A satellite formation for high-resolution SAR interferometry," IEEE Trans. Geosci. Remote Sens., vol. 45, no. 11, pp. 3317-3341, Nov. 2007.

[31] D. E. Barrick, M. W. Evans, and B. L. Weber, "Ocean surface currents mapped by radar," Science, vol. 198, pp. 138-144, Oct. 1977.

[32] K. W. Gurgel, H. H. Essen, and S. P. Kingsley, "High-frequency radars: Physical limitations and recent developments," Coastal Eng., vol. 37, pp. 201-218, Aug. 1999.

[33] E. V. Stanev, F. Ziemer, J. Schulz-Stellenfleth, J. Seemann, J. Staneva, and K. W. Gurgel, "Blending surface currents from HF radar observations and numerical modeling: Tidal hindcasts and forecasts," J. Atmos. Ocean. Technol., vol. 32, pp. 256-281, Feb. 2015.

[34] C. S. Chen, H. D. Liu, and R. C. Beardsley, "An unstructured grid, finitevolume, three-dimensional, primitive equations ocean model: Application to coastal ocean and estuaries," J. Atmos. Ocean. Technol., vol. 20 , pp. 159-186, Jan. 2003

[35] G. D. Egbert and S. Y. Erofeeva, "Efficient inverse modeling of barotropic ocean tides," J. Atmos. Ocean. Technol., vol. 19, pp. 183-204, Feb. 2002.

[36] X. M. Li, L. Q. Chi, X. E. Chen, Y. Z. Ren, and S. Lehner, "SAR observation and numerical modeling of tidal current wakes at the East China Sea offshore wind farm," J. Geophys. Res.-Oceans, vol. 119, no. 8, pp. 4958-4971, Aug. 2014

[37] J. Wright, "A new model for sea clutter," IEEE Trans. Antennas Propag., vol. 16, no. 2, pp. 217-223, Mar. 1968.
[38] S. Y. Kim, E. J. Terrill, and B. D. Cornuelle, "Mapping surface currents from HF radar radial velocity measurements using optimal interpolation," J. Geophys. Res.-Oceans, vol. 113, no. C10, pp. 26012613, Oct. 2008.

[39] R. Romeiser and W. Alpers, "An improved composite surface model for the radar backscattering cross section of the ocean surface: 2 . Model response to surface roughness variations and the radar imaging of underwater bottom topography," J. Geophys. Res.-Oceans, vol. 102, pp. 25251-25267, Nov. 1997.

[40] R. Romeiser, W. Alpers, and V. Wismann, "An improved composite surface model for the radar backscattering cross section of the ocean surface: 1. Theory of the model and optimization/validation by scatterometer data," J. Geophys. Res.-Oceans, vol. 102, no. C11, pp. 25237-25250, Nov. 1997.

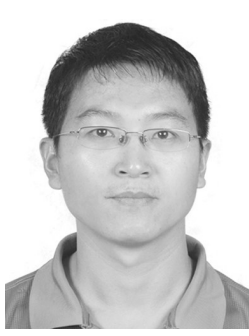

Yongzheng Ren received the B.E. degree in computer science from Jilin University, Changchun, China, in 2004, and the Ph.D. degree in physical oceanography from the Ocean University of China, Qingdao, China, in 2009.

Since 2009, he has been with the Key Laboratory of Digital Earth Science, Institute of Remote Sensing and Digital Earth, Chinese Academy of Sciences, Beijing, China. His research interests include satellite remote sensing of ocean currents, winds, and salinity by various microwave sensors.

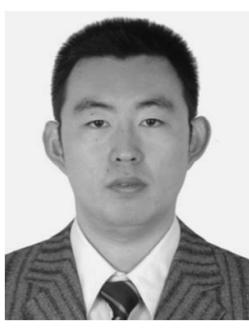

Xiao-Ming Li (M'14) received the B.S. degree in electronic and information engineering from Xi'an Communication College, Xi'an, China, in 2002, the (equivalent) M.S. degree from the Ocean University of China, Qingdao, China, in 2006, with a focus on satellite ocean remote sensing, and the Ph.D. degree in geophysics from the University of Hamburg, Hamburg, Germany, in 2010.

From 2006 to 2014, he was with the Remote Sensing Technology Institute, German Aerospace Center (DLR), Wessling, Germany. Since 2014, he has been with the Key Laboratory of Digital Earth Science, Institute of Remote Sensing and Digital Earth, Chinese Academy of Sciences, Beijing, China. His research interests include synthetic aperture radar ocean wave algorithm development, investigation of extremely oceanic weather, and observation of ocean dynamics using spaceborne multisensors.

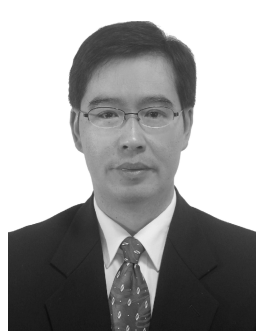

GuoPing Gao received the B.Sc. degree in meteorology from the Ocean University of China, Qingdao, China, in 1994, and the Ph.D. degree in marine science from the School of Marine Science and Technology, University of Massachusetts Dartmouth, Dartmouth, MA, USA, in 2011.

From 1994 to 2005, he was an Engineer at Ocean Observation, Ocean University of China. From 2005 to 2006, he was a Visiting Scholar with the University of Massachusetts Dartmouth. He is currently a Professor with the College of Marine Sciences, Shanghai Ocean University, Shanghai, China. His research interests include ocean general circulation and dynamics, polar oceanography, ocean observation, and numerical modeling.

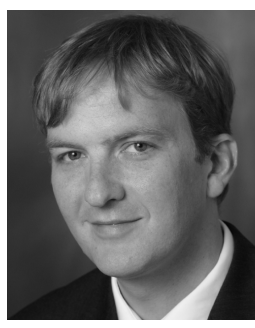

Thomas Edmund Busche received the diploma degree in geography from Georg-August-University, Goettingen, Germany, in 2000 .

From 2000 to 2002, he was with the private sector, involved in the field of remote sensing and the Geographic Information System. From 2003 to 2007, he was a Research Assistant at the Alfred Wegener Institute for Polar and Marine Research, Bremerhaven, Germany, and the Sea Ice Physics working group. Since 2007, he has been with the German Aerospace Center (DLR) and the Microwaves and Radar Institute, and the Polarimetric Interferometry working group in Oberpfaffenhofen, Germany. He is currently involved in all aspects of science coordination activities of DLR's TanDEM-X mission. 